\title{
PERBANDINGAN ASOSSIATION RULE BERBENTUK BINER DAN FUZZY C- PARTITION PADA ANALISIS MARKET BASKET DALAM DATA MINING
}

\author{
Altien J. Rindengan ${ }^{1\}}$ \\ 1) Program Studi Matematika, Fakultas Matematika dan Ilmu Pengetahuan Alam, \\ Universitas Sam Ratulangi, Manado \\ Jl. Kampus Unsrat Manado, 95115 \\ e-mail : altien@unsrat.ac.id
}

\begin{abstract}
ABSTRAK
Salah satu analisis dalam data mining adalah market basket analysis untuk menganalisa kecenderungan pembelian suatu barang yang berasosiasi dengan barang yang lain. Dalam tulisan ini membahas aturan asosiasinya dengan mempertimbangkan jumlah item barang yang dibeli dalam satu transaksi. Asumsinya adalah keterkaitan pembelian suatu barang dengan barang yang lain dalam satu transaksi akan semakin kecil jika jumlah item barang yang dibeli semakin banyak. Tulisan ini menganalisa asosisasi antar item barang dengan membuat tabel transaksi dalam bentuk nilai fuzzy set dibandingkan dengan analisa asosiasi yang biasa dilakukan dalam bentuk biner. Berdasarkan analisis terhadap data yang digunakan memberikan hasil support dan confidence yang cenderung lebih kecil tetapi lebih realistis dibanding aturan asosisasi biasa.
\end{abstract}

Keywords: analisis market basket, association rule, data mining, fuzzy c-partition.

\section{COMPARISON OF ASSOCIATION RULE WITH BINARY AND FUZZY C- PARTITION FORM AT MARKET BASKET ANALYSIS ON DATA MINING}

\begin{abstract}
One analysis in data mining is market basket analysis to analyze the purchase of a good trends associated with other items. In this paper discussing the association rules by considering the number of items purchased in one transaction. The assumption is that the purchase of a good relationship with the other items in one transaction will be smaller if the number of items purchased items more and more. This paper analyzes the association between the items of goods by making the transaction table in the form of fuzzy sets of values to compare with analysis of the usual associations in binary form. Based on the analysis of the data used to support and confidence of which tend to be smaller but more realistic than usual asosisasi rules.
\end{abstract}

Keywords: market basket analysis, association rule, data mining, fuzzy c-partition.

\section{PENDAHULUAN}

Market basket adalah istilah untuk menggambarkan kelompok barang yang cenderung dibeli oleh seorang konsumen dalam satu transaksi (misalkan di suatu supermarket). Misalkan kecenderungan membeli barang $X$ jika ia membeli barang $Y$, demikian sebaliknya. Dari sisi pengelola supermarket bisa diperoleh informasi untuk mengantisipasi hal ini, misalkan dengan menempatkan kedua barang tersebut pada tempat yang saling berdekatan agar mudah diperoleh konsumen.

Dalam data mining, metode yang biasa digunakan untuk menganalisis market basket adalah metode apriori. Metode ini adalah suatu algoritma dalam pencarian frekuensi barang dengan association rule, dimana metode ini cenderung menfokuskan pada hubungan antar barang dalam keseluruhan 
transaksi saja tanpa memperhatikan hubungan tiap barang dalam tiap transaksi. Misalkan hubungan antara barang $X$ dan $Y$ hanya dihitung berapa kali keduanya muncul dalam keseluruhan tansaksi tanpa memperhatikan jumlah barang yang terdapat dalam transaksi yang terdapat kedua barang tersebut. Akan tetapi, ada kemungkinan pembelian barang $X$ atau $Y$ tersebut dipengaruhi oleh pembelian barang yang lain sehingga akan memberikan hasil yang kurang akurat. Oleh karena itu perlu dianalisa hubungan antar barang yang bisa dilakukan dengan membuat tabel transaksi dalam bentuk fuzzy c-partition. Dimana metode ini dipakai untuk mengklasifikasi elemen-elemen dari suatu himpunan secara umum menjadi partisi-partisi berupa himpunan fuzzy. Konsep yang dilihat adalah bahwa suatu elemen akan memiliki hubungan/similarity dengan elemen lain jika ada dalam kelompok/class yang sama. Elemen-elemen tersebut akan memiliki hubungan yang lebih kuat jika sering berada dalam kelompok yang sama, tetapi dengan semakin banyaknya jumlah elemen pada suatu kelompok akan mengurangi derajat similarity antar tiap elemen dalam kelompok tersebut.

Beberapa penelitian sebelumnya yang berhubungan dengan tulisan ini adalah tentang alat analisis untuk market basket analysis (Auslender, 2004), fuzzy association rule (Intan, 2006 dan. Helm, 2007), dan derajat kesamaan dalam fuzzy partition (Intan, 2002)

Tujuan dari tulisan ini adalah untuk mengetahui tingkat asosiasi antar barang dalam tabel transaksi yang dinyatakan dalam bentuk fuzzy c-partition. Ini akan berguna untuk membantu pengambil keputusan dalam menentukan kebijakan pemasaran di lingkungan usahanya.

\section{TINJAUAN PUSTAKA}

\section{Market Basket Analysis}

Market basket analysis adalah salah satu cara yang digunakan untuk menganalisis data penjualan dari suatu perusahaan. Proses ini menganalisis perilaku pembelian konsumen dengan melihat asosiasi antar item-item yang berbeda pada tiap transaksi pembelian (Han dan Kamber, 2006). Dengan melihat hubungan kegunaan item-item, beberapa diantaranya mudah diperkirakan item apa saja yang dibeli secata bersamaan, misalnya kopi dan gula, sehingga antisipasi ketersediaan kopi akan sama dengan gula. Namun mungkin saja ada pola pembelian item yang tidak diperkirakan sebelumnya, misalnya gula dan sabun yang tidak mempunyai hubungan sebagai barang substitusi atau komplementer, sehingga akan terjadi kesalahan dalam mengantisipasi ketersediaan gula atau sabun tersebut. Inilah salah satu manfaat yang dapat diperoleh dari melakukan market basket analysis. Dengan melakukan analisa ini, seorang manajer tidak perlu mengalami kesulitan untuk menemukan pola pembelian item apa saja yang mungkin dibeli secara bersamaan, karena data dari transaksi penjualan akan memberitahukannya sendiri. Dalam data mining, analisa ini dilakukan dengan association rule.

\section{Association Rule}

Association rule mining adalah suatu prosedur untuk mencari hubungan antar item dalam suatu data set yang ditentukan (Han dan Kamber, 2006). Association rule meliputi dua tahap yaitu mencari kombinasi yang paling sering terjadi dari suatu itemset dan mendefinsikan condition dan result (untuk conditional association rule). Masalah mendasar dari analisis asosiasi adalah bagaimana menemukan kaidah dalam bentuk set_1 $\rightarrow$ set_2 (Possas,. Wagner,. Marcio dan Rodolfo, 2000). Dalam menentukan suatu association rule, terdapat suatu interestingness measure (ukuran kepercayaan) yang didapatkan dari hasil pengolahan data dengan perhitungan tertentu, yaitu:

- support: suatu ukuran yang menunjukkan seberapa besar tingkat dominasi suatu 
item/itemset dari keseluruhan transaksi. Ukuran ini menentukan apakah suatu item/itemset layak untuk dicari confidence-nya (misal, dari keseluruhan transaksi yang ada, seberapa besar tingkat dominasi yang menunjukkan bahwa item $A$ dan $B$ dibeli bersamaan).

- confidence: suatu ukuran yang menunjukkan hubungan antar 2 item secara conditional (misal, seberapa sering item $B$ dibeli jika orang membeli item $A$ ).

Misalkan item $A$ dan $B$ dalam total transaksi, maka support $(A)$ adalah jumlah transaksi yang ada $A$ dibagi total transaksi yang disebut support 1-item set, dan $\operatorname{support}(A$ atau $B)$ adalah transaksi yang ada $A$ dan $B$ dibagi total transaksi yang disebut support 2-item set. Demikian selanjutnya untuk item barang yang lebih banyak. Sedangkan confidence dianalisa mulai dari 2 barang karena berhubungan dengan keinginan membeli barang secara bersamaan. Rumusannya adalah confidence $(A \rightarrow B)$ sama dengan support $(A$ atau $B)$ dibagi support $(A)$. Perhatikan bahwa akan beda perhitungan dengan confidence $(B \rightarrow A)$. Demikian untuk item barang yang lebih banyak.

Definisi formal untuk kedua ukuran ini dapat dirumuskan:

$$
\begin{aligned}
& \text { support }(X \rightarrow \mathrm{Y})=\sigma(X \cup Y) / N \\
& \text { confidence }(X \rightarrow \mathrm{Y})=\sigma(X \cup Y) / \sigma(X)
\end{aligned}
$$

(Tan, Steinbach dan Kumar, 2006)

Kedua ukuran ini nantinya berguna dalam menentukan interesting association rules, yaitu untuk dibandingkan dengan batasan (threshold) yang ditentukan oleh user. Batasan tersebut umumnya terdiri dari min_support dan min_confidence. Contoh (suatu association rule), If $A$ then $B$ [support $=3 \%$, confidence $=70 \%]$, dimana $A$ dan $B$ adalah kumpulan item yang dibeli oleh konsumen perusahaan $Z$. Artinya: item $A$ dan $B$ dibeli bersamaan sebesar $3 \%$ dari keseluruhan data transaksi yang dianalisis dan $70 \%$ dari semua konsumen yang membeli item $A$ juga membeli item $B$. Dari contoh di atas, jika support-nya $\geq$ min_support dan confidence-nya $\geq$ min_confidence, maka rule tersebut bisa dikatakan sebagai interesting rule.

\section{Algoritma Apriori}

Dalam Han dan Kamber, 2006, didefiniskan bahwa "apriori is an influental algorithm for mining frequent itemsets for Boolean association rules". Apriori adalah suatu algoritma yang sudah sangat dikenal dalam melakukan pencarian frequent itemset dengan association rule. Sesuai dengan namanya, algoritma ini menggunakan knowledge mengenai frequent itemset yang telah diketahui sebelumnya, untuk memproses informasi selanjutnya. Algoritma inilah yang biasanya dipakai dalam proses data mining untuk market basket analysis. Algoritma apriori memakai pendekatan iterative (level-wise search), dimana $k$ itemset dipakai untuk menyelidiki $(k+1)$ itemset. Langkah-langkah dari algoritma ini adalah sebagai berikut (Ulmer, 2002):

1. Set $k=1$ (menunjuk pada itemset ke-1).

2. Hitung semua $k$-itemset (itemset yang mempunyai $k$-item).

3. Hitung support dari semua calon itemset. Pilih itemset tersebut berdasarkan perhitungan minimum support.

4. Gabungkan semua $k$-sized itemset untuk menghasilkan calon itemset $k+1$.

5. Set $k=k+1$.

6. Ulangi langkah 3-5 sampai tidak ada itemset yang lebih besar yang dapat dibentuk.

7. Buat final set dari itemset dengan menciptakan suatu union dari semua $k$ itemset.

Contohnya, jika ada 10 transaksi $(\mathrm{T} 1, \mathrm{~T} 2, \ldots, \mathrm{T} 10)$ untuk 5 item barang (B1,B2,...,B5) seperti pada Tabel 1, maka : 
Tabel 1 Contoh 1 transaksi dengan 5 item barang

\begin{tabular}{|c|c|c|c|c|c|}
\hline & B1 & B2 & B3 & B4 & B5 \\
\hline T1 & 1 & 1 & 0 & 1 & 1 \\
\hline T2 & 1 & 1 & 1 & 0 & 1 \\
\hline T3 & 0 & 0 & 1 & 0 & 0 \\
\hline T4 & 1 & 1 & 0 & 1 & 1 \\
\hline T5 & 1 & 1 & 0 & 1 & 1 \\
\hline T6 & 0 & 1 & 0 & 0 & 1 \\
\hline T7 & 1 & 1 & 0 & 0 & 1 \\
\hline T8 & 0 & 0 & 0 & 1 & 1 \\
\hline T9 & 1 & 1 & 1 & 0 & 1 \\
\hline T10 & 0 & 1 & 1 & 1 & 0 \\
\hline
\end{tabular}

Support untuk 1-item set adalah: $\operatorname{support}(\mathrm{B} 1)=60 \%$, $\operatorname{support}(\mathrm{B} 2)=80 \%$, $\operatorname{support}(\mathrm{B} 3)=40 \%$, $\operatorname{support}(\mathrm{B} 4)=50 \%$, support(B5) $=80 \%$.

Jika ditetapkan min_support $=60 \%$, maka yang memenuhi hanya B1, B2, dan B3. Selanjutnya untuk 2-item set hanya dianalisa pada kombinasi 1-item set yang memenuhi min_support yaitu kombinasi dari B1, B2, dan B3. Jika dihitung, diperoleh: $\operatorname{support}(\mathrm{B} 1 \cup \mathrm{B} 2)=60 \%$, $\operatorname{support}(\mathrm{B} 1 \cup \mathrm{B} 5)=60 \%$, $\operatorname{support}(\mathrm{B} 2 \cup \mathrm{B} 5)=70 \%$.

Jika min_support sama, maka ketiga kombinasi ini memenuhi. Untuk 3-item set, diperoleh $\operatorname{support}(\mathrm{B} 1 \cup \mathrm{B} 2 \cup \mathrm{B} 5)=60 \%$ yang memenuhi min_support. Jika selanjutnya dihitung nilai confidence-nya dengan menetapkan min_confidence sebesar $80 \%$ maka diperoleh interesting rule sebagai berikut:

If B1 than B2 (support $=60 \%$, confidence $=100 \%)$ If B1 than B5 (support $=60 \%$, confidence $=100 \%$ ) If B2 than B5 (support $=70 \%$, confidence $=87.5 \%$ ) If B5 than B2 (support $=70 \%$, confidence $=87.5 \%$ ) If $\mathrm{B} 1$ than $(\mathrm{B} 2 \cup \mathrm{B} 5)$ ( support $=60 \%$, confidence $=100 \%)$

If $(\mathrm{B} 1 \cup \mathrm{B} 2)$ than $\mathrm{B} 5$ (support $=60 \%$, confidence $=100 \%$ )

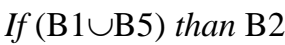
( support $=60 \%$, confidence $=100 \%$ ) If $(\mathrm{B} 2 \cup \mathrm{B} 5)$ than $\mathrm{B} 1$ ( support $=60 \%$, confidence $=87.5 \%$ ).

\section{Fuzzy c-Partition}

Menurut (Klir dan Yuan, 2001), fuzzy cpartition dapat didefinisikan sebagai berikut: Misalkan $I=\left\{i_{1}, i_{2}, \ldots, i_{3}\right\}$ adalah domain dari data. Fuzzy c-partition dari $I$ adalah fuzzy subset atau fuzzy classes dari $T=\left\{t_{1}, t_{2}, \ldots\right.$, $\left.t_{3}\right\}$, yang memenuhi:

$\sum_{m=1}^{c} \mu t_{m}\left(i_{k}\right)=1$

untuk semua $k \in N_{n}$

$0<\sum_{k=1}^{c} \mu t_{m}\left(i_{k}\right)<n$

untuk semua $m \in N_{c}$

dimana $\mu t_{m}\left(i_{k}\right) \in[0,1]$

Fuzzy c-Covering

Fuzzy c-covering merupakan salah satu metode yang dipakai untuk mengklasifikasikan elemen-elemen dari suatu himpunan universal menjadi partisi-partisi berupa fuzzy sets. Fuzzy c-covering merupakan generalisasi dari metode fuzzy $c$ partition pada persamaan (1) menjadi :

$\sum_{m=1}^{c} \mu t_{m}\left(i_{k}\right) \geq 1$

untuk semua $k \in N_{n}$.

\section{Degree of Similarity in Fuzzy c-Covering}

Setiap crisp element dari data pada $I$ juga dapat direpresentasikan sebagai fuzzy set dari fuzzy classes ( $T$ ) dengan rumus (Intan dan Masao, 2003):

$\mu_{i_{m}}\left(t_{j}\right)=\frac{\mu_{t_{j}}\left(i_{m}\right)}{\sum_{t \epsilon I} \mu_{t_{j}}(i)}$

dimana $\mu_{t_{j}}\left(i_{m}\right)$ adalah nilai fuzzy partisi $t_{j}$ pada elemen $i_{m}$ dan $\sum_{t \in I} \mu_{t_{j}}(i)$ adalah penjumlahan nilai fuzzy partisi $t_{j}$ pada semua elemen dalam domain $I$.

Dalam model pembelian barang, $t_{j}$ berhubungan dengan nomor transaksi (transaksi ke-j) dan elemen $i_{m}$ berhubungan dengan jenis barang ke- $m$ dalam transaksi pembelian.

\section{METODOLOGI}

Algoritma ini didasari bahwa untuk mencari hubungan antar item berdasarkan pada persepsi bahwa semakin banyak item yang dibeli dalam satu transaksi maka hubungan antar item yang terdapat dalam 
transaksi ini semakin lemah. Ini untuk memperbaiki algoritma apriori yang tidak mempertimbangkan hal ini.

Data yang digunakan dalam tulisan ini diunduh dari http://www.csd.abdn.ac.uk/ hnguyen/teaching/CS553/marketbasket.csv.

Sebelum data ini digunakan dalam algoritma yang ada, dilakukan tahap praproses data terlebih dahulu. Data asli dalam tabel transaksi berisi nilai true jika dibeli dan false jika tidak dibeli, dibuat dulu dalam data biner (0-1) artinya jika ada pembelian dinyatakan 1 dan jika tidak ada pembelian disimbolkan 0 . Data 0-1 ini, kemudian dinyatakan dalam fuzzy set seperti pada persamaan (4). Baru kemudian dianalisa dengan algoritma yang ada. Analisis data yang dilakukan menggunakan program Microsoft Excel 2007 dan Orange 2.0b.

Langkah-langkah algoritma ini adalah :

- Menentukan min_support ke-k sebagai threshold bagi kombinasi $k$-item terhadap tingkat dominasinya dari keseluruhan transaksi.

- Mencari support dari setiap kombinasi $k$ item yang memungkinkan yang ada di dalam transaksi.

- Melakukan penyaringan terhadap kombinasi item yang ada di dalam transaksi tersebut yang tidak memenuhi: support $(p) \geq$ min_support ke- $k$.

- Mencari kombinasi k-item yang memungkinkan dari tiap kombinasi $(k-1)$ item yang memenuhi minimum support yang telah ditentukan.

- Mencari candidate rules dengan cara menghitung confidence dari setiap kombinasi $k$-item yang memenuhi min_support ke- $k(k \geq 2$.)

Dalam perhitungan support $k$-item, misalkan dalam transaksi $t$ terjadi pembelian barang $\{a, b, d, f\}$, dari kumpulan barang $\{a, b, c, d, e, f\}$ maka nilai keenam barang tersebut dalam tabel transaksi yang akan dianalisa adalah $\quad\{a, b, c, d, e, f\}=$ $\{1 / 4,1 / 4,0,1 / 4,0,1 / 4\}$ atau bisa dinyatakan : $1 /$ (jumlah barang yang dibeli), jika barang tersebut dibeli; dan 0, jika barang tersebut tidak dibeli. Ini berdasarkan persamaan (4).

Misalkan tabel transaksi di Tabel 1, diubah dalam fuzzy set menjadi:

Tabel 2 Tabel transaksi dalam bentuk nilai

fuzzy set
\begin{tabular}{|c|c|c|c|c|c|}
\hline & B1 & B 2 & B3 & B 4 & B 5 \\
\hline T1 & $1 / 4$ & $1 / 4$ & 0 & $1 / 4$ & $1 / 4$ \\
\hline T2 & $1 / 4$ & $1 / 4$ & $1 / 4$ & 0 & $1 / 4$ \\
\hline T3 & 0 & 0 & 1 & 0 & 0 \\
\hline T4 & $1 / 4$ & $1 / 4$ & 0 & $1 / 4$ & $1 / 4$ \\
\hline T5 & $1 / 4$ & $1 / 4$ & 0 & $1 / 4$ & $1 / 4$ \\
\hline T6 & 0 & $1 / 2$ & 0 & 0 & $1 / 2$ \\
\hline T7 & $1 / 3$ & $1 / 3$ & 0 & 0 & $1 / 3$ \\
\hline T8 & 0 & 0 & 0 & $1 / 2$ & $1 / 2$ \\
\hline T9 & $1 / 4$ & $1 / 4$ & $1 / 4$ & 0 & $1 / 4$ \\
\hline T10 & 0 & $1 / 3$ & $1 / 3$ & $1 / 3$ & 0 \\
\hline
\end{tabular}

Jika dibandingkan antara Tabel 1 dan Tabel 2, sebagai contoh yaitu pada Tabel 1, hubungan kedekatan item B4 dan B5 sebesar 1(keduanya ada) pada transaksi $\mathrm{T} 1$ dan $\mathrm{T} 8$. Tapi dalam Tabel 2 dengan memperhitungkan asumsi yang ada, maka hubungan kedekatannya item B4 dan B5 berbeda yaitu pada transaksi $\mathrm{T} 1$ sebesar $1 / 4$ dan pada T8 sebesar 1/2.

Sekarang akan dihitung support untuk 1-item set, diperoleh : $\operatorname{support}(\mathrm{B} 1)=0.158$, $\operatorname{support}(\mathrm{B} 2)=0.242, \operatorname{support}(\mathrm{B} 3)=0.183$, $\operatorname{support}(\mathrm{B} 4)=0.158, \operatorname{support}(\mathrm{B} 5)=0.258$.

Jika ditetapkan min_support sebesar $20 \%$ maka yang memenuhi hanya B2 dan B5. Selanjutnya dihitung support untuk 2-item set, diperoleh: support $(\mathrm{B} 2 \cup \mathrm{B} 5)=0.208$.

Perhatikan bahwa nilai support yang diperoleh cenderung lebih kecil dibandingkan dengan menggunakan association rule biasa. Selain itu nilai yang diperoleh memberikan perbedaan urutan dari yang terbesar ke terkecil atau sebaliknya. Dengan menggunakan association rule biasa diperoleh urutan nilai support dari besar ke kecil adalah (B2,B5), B1, B4, B3. Sedangkan dengan algoritma ini diperoleh urutan B5, B3, (B1,B4), B2.

Selanjutnya dihitung confidence-nya, diperoleh: confidence $(\mathrm{B} 2 \rightarrow \mathrm{B} 5)=0.862$ dan confidence $(\mathrm{B} 5 \rightarrow \mathrm{B} 2)=0.806$. Jika ditetapkan 
min_confidence sebesar $85 \%$ maka interesting rule yang diperoleh adalah:

if $\mathrm{B} 2$ then $\mathrm{B} 5$

[ support $=20.8 \%$, confidence $=86.2 \%$ ], memberikan nilai yang cederung lebih kecil dibandingkan dengan menggunakan association rule berbentuk biner dari Tabel 1 .

\section{HASIL DAN PEMBAHASAN}

Berdasarkan analisis terhadap data dengan menetapkan min_support sebesar $1.5 \%$ untuk setiap 1-item set, dari 303 item diperoleh hanya 5 item barang yang memenuhi min_support yaitu barang White Bread (WB), Potato Chips (PC), Toilet Paper (TP), Cream Cheese (CC), dan Sweet Relish (SR), dengan nilai support-nya berturut-turut adalah: 0.02585, 0.02224, 0.01727, 0.01651, 0.01650 .

Selanjutnya, berdasarkan barangbarang yang memenuhi support 1-item set dihitung support untuk 2-item set barang yang memenuhi min_support $0.1 \%$ dan diperoleh:

$$
\begin{aligned}
& \operatorname{support}(\mathrm{WB} \cup \mathrm{PC})=0.00336 \\
& \operatorname{support}(\mathrm{WB} \cup \mathrm{TP})=0.00117 \\
& \operatorname{support}(\mathrm{PC} \cup \mathrm{TP})=0.00105 \\
& \operatorname{support}(\mathrm{CC} \cup \mathrm{SR})=0.00173
\end{aligned}
$$

Penentuan min_support $0.1 \%$, tidak sama dengan min_support 1-item set karena tidak ada yang memenuhi $1.5 \%$. Makin mengecilnya nilai support karena sudah melibatkan kombinasi 2 barang yang muncul bersamaan dalam tiap transaksi. Kemudian untuk 3-item set barang, diperoleh $\operatorname{support}(\mathrm{WB} \cup \mathrm{PC} \cup \mathrm{TP})=0.00055$.

Selanjutnya confidence yang diperoleh, dengan menetapkan min_confidence sebesar $10 \%$, disajikan dalam Tabel 3 berikut.
Tabel 3 Nilai confidence pembelian kombinasi barang

\begin{tabular}{|c|c|}
\hline Aturan Pembelian & Nilai confidence \\
\hline $\mathrm{WB} \rightarrow \mathrm{PC}$ & 0.1300 \\
\hline $\mathrm{PC} \rightarrow \mathrm{WB}$ & 0.1511 \\
\hline $\mathrm{CC} \rightarrow \mathrm{SR}$ & 0.1047 \\
\hline $\mathrm{SR} \rightarrow \mathrm{CC}$ & 0.1048 \\
\hline $\mathrm{WB}, \mathrm{PC} \rightarrow \mathrm{TP}$ & 0.1636 \\
\hline $\mathrm{WB}, \mathrm{TP} \rightarrow \mathrm{PC}$ & 0.4688 \\
\hline $\mathrm{PC}, \mathrm{TP} \rightarrow \mathrm{WB}$ & 0.5229 \\
\hline
\end{tabular}

Berdasarkan Tabel 3 ini dapat dibuat suatu interesting rule yang memenuhi min_confidence $10 \%$ sebagai berikut :

- Jika beli White Bread maka beli Potato Chips

[support $=0.336 \%$, confidence $=13 \%]$

- Jika beli Potato Chips maka beli White Bread [ support $=0.336 \%$, confidence $=15.11 \%$ ]

- Jika beli Cream Cheese maka beli Sweet Relish [ support $=0.173 \%$, confidence $=10.47 \%$ ]

- Jika beli Sweet Relish maka beli Cream Cheese [support $=0.173 \%$, confidence $=10.48 \%$ ]

- Jika beli (White Bread dan Potato Chips) maka beli Toilet Paper [support $=0.055 \%$, confidence $=16.36 \%$ ]

- Jika beli (White Bread dan Toilet Paper) maka beli Potato Chips [ support $=0.055 \%$, confidence $=46.88 \%$ ]

- Jika beli (Potato Chips dan Toilet Paper) maka beli White Bread [ support $=0.055 \%$, confidence $=52.29 \%$ ] Jika dihitung juga nilai support dan confidence menggunakan association rule berbentuk biner pada k-item set diatas, diperoleh :

$\operatorname{support}(\mathrm{WB})=0.149$

$\operatorname{support}(\mathrm{PC})=0.119$

$\operatorname{support}(\mathrm{TP})=0.101$

$\operatorname{support}(\mathrm{CC})=0.83$

$\operatorname{support}(\mathrm{SR})=0.95$

support $(\mathrm{WB} \cup \mathrm{PC})=0.71$

$\operatorname{support}(\mathrm{WB} \cup \mathrm{TP})=0.48$

$\operatorname{support}(\mathrm{PC} \cup \mathrm{TP})=0.54$

$\operatorname{support}(\mathrm{CC} \cup \mathrm{SR})=0.36$

$\operatorname{support}(\mathrm{WB} \cup \mathrm{PC} \cup \mathrm{TP})=0.36$ 
confidence $(\mathrm{WB} \rightarrow \mathrm{PC})=0.48$

confidence $(\mathrm{PC} \rightarrow \mathrm{WB})=0.60$

confidence $(\mathrm{CC} \rightarrow \mathrm{SR})=0.429$

confidence $(\mathrm{SR} \rightarrow \mathrm{CC})=0.375$

confidence $((\mathrm{WB} \cup \mathrm{PC}) \rightarrow \mathrm{TP})=0.5$

confidence $((\mathrm{WB} \cup \mathrm{TP}) \rightarrow \mathrm{PC})=0.75$

confidence $((\mathrm{PC} \cup \mathrm{TP}) \rightarrow \mathrm{WB})=0.667$.

Nilai support dan confidence yang diperoleh cenderung lebih kecil namun lebih realistis dibandingkan yang menggunakan association rule biasa, dikarenakan dalam perhitungannya menggunakan nilai fuzzy set yang menyatakan tingkat asosisasi antara item barang makin kecil dengan makin banyaknya barang yang dibeli dalam satu transaksi.

\section{KESIMPULAN}

Berdasarkan analisa dalam tulisan ini ternyata tabel transaksi bisa dinyatakan dalam bentuk fuzzy set yang mengasumsikan bahwa makin banyak barang yang dibeli dalam satu transaksi maka tingkat asosiasinya makin kecil.

Dibandingkan dengan menggunakan association rule berbentuk biner, dengan menggunakan fuzzy c-partition memberikan nilai support dan confidence cenderung lebih kecil tapi ini memberikan hasil yang lebih realistis.

\section{DAFTAR PUSTAKA}

Auslender L.E. 2004. On Analytical Tools for Market Basket Analysis. SAS Institute, Research \& Development. New York.

Han J., M. Kamber. 2006. Data Mining: Concepts and Techniques. Morgan Kaufmann Publisher.
Helm L. 2007. Fuzzy Association Rules. An Implementation in $R$ [Thesis]. Vienna University. Vienna.

http://www.csd.abdn.ac.uk/ hnguyen/ teaching/ CS5553/marketbasket.csv.

Intan R. 2002. Degree of Similarity in Fuzzy Partition. Lecture Notes in Computer Science 2275:99-107.

Intan R. 2006. A Proposal of Multidimensional Association Rules. Jurnal Informatika 7(2): 85-90.

Intan R., M. Masao. 2003. A Proposal of Fuzzy Thesaurus Generated by Fuzzy Covering. IEEE. 2003: 167-172.

Klir G. J., B.Yuan. 2001. Fuzzy Sets and Fuzzy Logic-Theory and Applications. Prentice Hall India.

Possas B., M. Wagner, C. Marcio, R. Rodolfo, 2000. Using Quantitative Information for Efficient Association Rule Generation, ACM SIGMOD 29:19-25.

http://csis.pace.edu/csis/masplas/p8.pdf

Tan P.N., M. Steinbach, V. Kumar. 2006. Introduction to Data Mining. Addison Wesley. Boston.

Ulmer D. 2002. Mining an Online Auctions Data Warehouse, Proceedings of MASPLAS'02 The Mid-Atlantic Student Workshop on Programming Languages and Systems, Pace University. 